\title{
Properties of the Mangrove Community Sediment on the Island of El Souda Western Saudi Arabia
}

\author{
Ebtisam Hassan Awari ${ }^{1} \&$ Amal Mohamed Jan Mullah ${ }^{1}$ \\ ${ }^{1}$ Department of Geography and Geographic Information system, Faculty of Arts \& Humanities, King Abdulaziz \\ University, Jeddah, Saudi Arabia \\ Correspondence: Ebtisam Hassan Awari, Department of Geography and Geographic Information system, Faculty \\ of Arts \& Humanities, King Abdulaziz University, Jeddah, Saudi Arabia. E-mail: eawari@kau.edu.sa
}

\author{
Received: March 17, 2014 Accepted: April 21, 2014 Online Published: May 15, 2014 \\ doi:10.5539/jas.v6n6p165 URL: http://dx.doi.org/10.5539/jas.v6n6p165
}

\begin{abstract}
Blue carbon refers to the carbon captured by oceans and coastal ecosystems. The carbon captured by living organisms in oceans is stored in the form of biomass and sediments. Blue carbon is considered to be a modern trend to reduce emissions of carbon dioxide in the atmosphere and mitigate climate change. The aim was to understand the characteristics and nature of this ecosystem. Data on various parameters including sediment hydro chemical properties, vital nutrients and organic matter were determined across eight different sectors that were divided on the basis of age and density of mangrove forest. The study showed that sectors in the studied mangrove forest of El-Souda-West Island Kingdom of Saudi Arabia with older and denser trees gave more significant information on hydro chemical properties than sectors with younger trees. Weak relationship was found between the degree of alkalinity and the growth of mangroves. The distribution of dissolved oxygen values was irregular between the sectors. The results of vital nutrients showed that the highest values of nitrates were recorded in sector 7 and 8. Absence of organic pollution in the study area that was attributed to organic rich sediment that gets accumulated in the mangrove roots. In general the values of vital nutrients below the international limit. A strong relationship was observed between the organic content of the sediment (organic carbon oxidized, organic carbon, total, organic matter), and the density of mangroves. The study revealed the role of benthic organisms especially cancers in enriching the sediment organic matter beside the impact of the tide, and the nature of the soil, and the proximity and distance from the sea.
\end{abstract}

Keywords: biodiversity, blue carbon, El-Souda, mangrove communities, Red Sea Coast, Saudi Arabia

\section{Introduction}

Carbon Blue or what is known as Blue Carbon represents one of modern ideas to reduce emissions of carbon dioxide $\mathrm{CO}_{2}$ in the atmosphere, thus limit climate change (Sedjo \& Sohngen, 2012). This emphasizes the need to maintain reservoirs of organic carbon reduced in the sediments of wet lands environments whether mangrove forests or salt marshes or sea grass. All these have the ability to capture, store and sequestering carbon dioxide in the sediments for hundreds or even thousands of years (Tripati et al., 2009). This is an extraordinary repository of carbon in the world. Today mangrove forests represent the largest sinks of carbon in the world where store carbon 15-times more than the rest of the wet land and absorbed it for thousands of years (Margareth, 2011). However, recent studies have proven the retreat of mangrove forests by up to $35 \%$ of the total area of mangrove in the world (Rezende et al., 2006). Where Margareth (2011) estimated rate of decline in the range of 30\%-50\% over the last fifty years and Daniel et al. (2012) recorded a reduction of $10 \%-15 \%$ of the total volume of the world's mangrove forests. Mangrove forests are hot spots for biodiversity, they provide important and valuable ecosystem functions, including a large carbon sink capacity (Duarte et al., 2008; Duarte, 2009). Nelleman et al. (2009) reported that mangrove trees have the highest productivity of any forest ecosystem, but this tree (and the other blue carbon habitats) are being rapidly destroyed at a higher rate than tropical forests ecosystem, but this tree (and the other blue carbon habitats) are being rapidly destroyed at a higher rate than tropical forests (Spalding et al., 2010). Albert et al. (2012) indicated that in areas of high use and high population density, the cutting of mangroves causes a substantial loss of carbon from the aboveground biomass component. Therefore, maintain mangroves, and restoring growth is very important for its effectiveness in shorthand, and store and sequesters carbon in the form of deposits which will reduce the effects of climate change in the globe. This study was assigned in order to shed light on the properties of sediments member of the community mangrove on the island of Souda west of Saudi Arabia as 
a case study. The aim was to understand the characteristics and nature of this ecosystem with a high potential for interaction with the natural environmental conditions, and the ability to interact with low human interference.

\section{Materials and Methods}

\subsection{Study Area}

The island of El-Souda western Saudi Arabia is located on the Red Sea coast (south of the city of Jeddah) between latitudes $20^{\circ} 34^{\prime} 48^{\prime \prime}-20^{\circ} 35^{\prime} 24^{\prime \prime}$ and longitudes $39^{\circ} 34^{\prime} 12^{\prime \prime}-39^{\circ} 37^{\prime} 48^{\prime \prime}$ (Figure 1). The coast area consists of bays protected surrounded peninsula from the north and south forming a peninsula known locally as El-Souda island. This made an area protected from the waves which allowed the growth of mangroves in these coasts. It consist of sandy beaches punctuated by a number of bogs salt flat surface, and exposed to water immersion tide making it connected with the sea in the case of high tide.

The sand covering remaining parts of the coastal plain, mixed in some locations with gravel and limestone or coral in other areas which makes the appearance of the coastal plain sandy reg, except for areas that hurt the valleys coming from Mount Sita and the Valley Dam. The soil in the study area consist of a mixture of soils crude sandy desert sand torripsamments form beach dominant feature of her, and soils raw sand wet udipsamments westward, and soil epidural normal saline Solorthids (Map General of the soil, scale 1: 250.000, 1986), especially in the areas of bogs. The study field showed that soil texture ranging from silt Celtic to silt sandy by proximity and distance on the scope of mangroves in general.

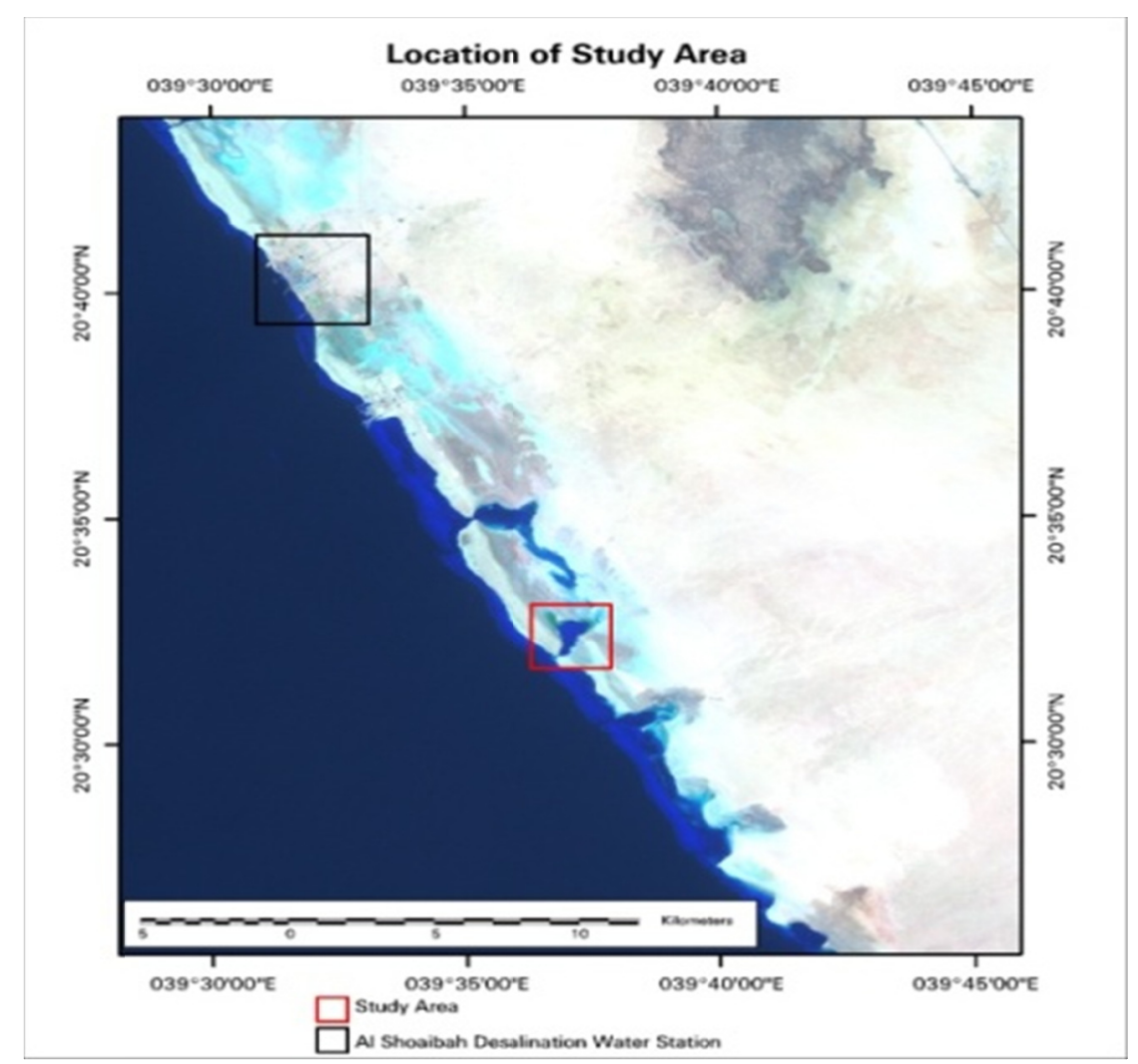

Figure 1. Location of the study area of El-Souda - West Island Kingdom of Saudi Arabia

\subsection{Field Data Processing}

To achieve the objectives of this study, the research was designed on several phases, which includes the monitoring of all environmental phenomena of the study area, whether literary survey data and field survey, which divided into several stages: 
1. A preliminary field survey was made to the study area, in which the forest site was divided into (8) sectors preview. These sectors where delineated on the basis of the variation between the different sites. The site description representing the eight sectors was shown in Figure 2.

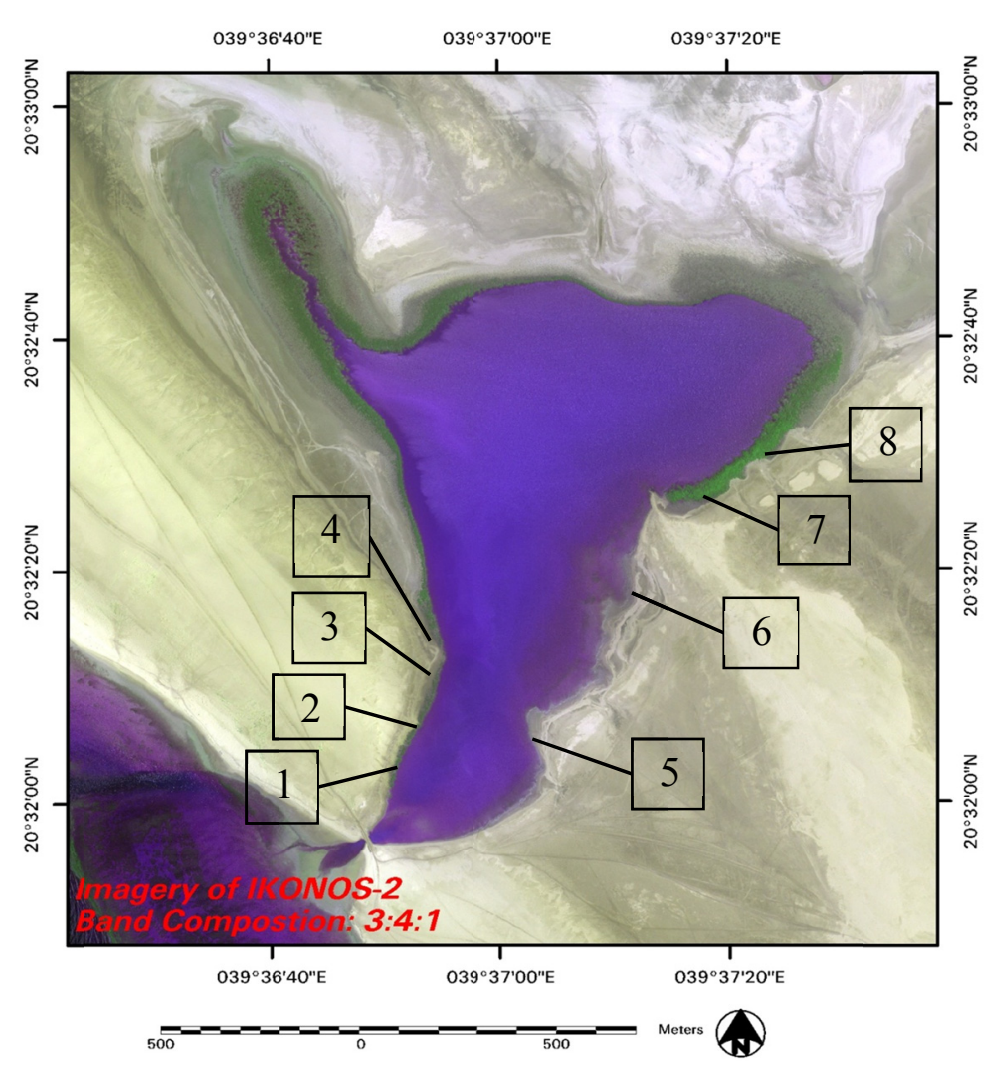

Figure 2. Site preview segments in the study area showing the eight observation sectors of El-Souda - West Island Kingdom of Saudi Arabia

2. The data were collected across the eight sectors during three visits to the field. First data collection was done on $14 / 02 / 2013$, on which 32 soil samples were collected devoted to the measurement of the physical properties of the soil. The second was on 25/04/2013, with 16 water samples were collected to measure Hydro chemical characteristics of the mangrove environment. The third was on 23/7/2013, with 24 samples were collected for organic deposits in the various sectors of the preview devoted to the measurement of organic carbon.

3. Sediment samples were analyzed according to (Walkley \& Black, 1934) in a laboratory soil stage of data processing. whereas maps and satellite images were processed through the analysis of visual space satellite American (IKONS) for the year 2012, especially when studying the sites of mangroves, and intervention sites human in the region.

4. The implementation phase of operations classification and statistical study of the relationship between the variables.

\section{Results and Discussion}

\subsection{Hydro Chemical Properties of the Water Mangrove community in El-Souda Island}

The results in (Table 1) reflected the values of hydro chemical indicators of water mangrove community in the study area and it can be concluded that:

$\mathrm{pH}$ values in the side of alkali ranged between $8.05-8.29$ (Figure 3). This indicates the presence of some alkaline salts, which are mostly salts of calcium carbonate. Where the sector 8 recorded lower ratio (8.05), and is due to the increase in the amount of organic waste falling from mangrove plants. This was in agreement with the results of (Marchand et al., 2011). 
The rates of salinity values in the preview segments ranged between $40.97 \%-42.58 \%$. Sectors 5 and 7 , had the highest values, but mostly similar to concentrations of salinity in the waters of the Red Sea. However compared to the global average of 32 to $37 \%$ salinity, it was higher. This may be attributed to the outskirts of coastal salt marsh, which may affect the increasing salinity of the water during the tsunami.

Table 1 . The average values $( \pm \mathrm{SD})$ of the properties Hydro chemical mangrove community water in eight sectors of El-Souda - West Island Kingdom of Saudi Arabia

\begin{tabular}{|c|c|c|c|c|c|c|c|c|c|}
\hline Property & Unit & Sector 1 & Sector 2 & Sector 3 & Sector 4 & Sector 5 & Sector 6 & Sector 7 & Sector 8 \\
\hline $\mathrm{pH}$ & -- & $8.17 \pm 0.41$ & $8.11 \pm 0.38$ & $8.19 \pm 0.43$ & $8.08 \pm 0.40$ & $8.16 \pm 0.41$ & $8.20 \pm 0.46$ & $8.12 \pm 0.41$ & $8.05 \pm 0.39$ \\
\hline Salinity & $\%$ & $41.01 \pm 4.87$ & $41.01 \pm 4.96$ & $40.99 \pm 4.08$ & $41.01 \pm 4.92$ & $40.97 \pm 4.10$ & $41.02 \pm 4.51$ & $42.58 \pm 4.26$ & $41.08 \pm 3.69$ \\
\hline $\begin{array}{l}\text { Alkaline } \\
\left(\mathrm{CaCO}_{3}\right)\end{array}$ & $\mathrm{mg} / 1$ & $145 \pm 15.95$ & $160 \pm 19.2$ & $150 \pm 15.3$ & $150 \pm 18.6$ & $135 \pm 13.77$ & $140 \pm 17.36$ & $215 \pm 27.09$ & $150 \pm 15.32$ \\
\hline $\begin{array}{l}\text { Dissolved } \\
\text { Oxygen (DO) }\end{array}$ & $\mathrm{mg} / \mathrm{l}$ & $3.15 \pm 0.28$ & $3.15 \pm 0.26$ & $5.50 \pm 0.51$ & $5.15 \pm 0.46$ & $6.15 \pm 0.52$ & $6.05 \pm 0.57$ & $6.20 \pm 0.56$ & $6.20 \pm 0.51$ \\
\hline $\begin{array}{l}\text { Biochemical } \\
\text { oxygen } \\
\text { requirement } \\
\text { (BOD) }\end{array}$ & $\mathrm{mg} / \mathrm{l}$ & $>5 \pm 0.65$ & $>5 \pm 0.63$ & $>5 \pm 0.56$ & $>5 \pm 0.54$ & $>5 \pm 0.50$ & $>5 \pm 0.51$ & $>5 \pm 0.53$ & $>5 \pm 0.52$ \\
\hline $\begin{array}{l}\text { chemical } \\
\text { oxygen } \\
\text { requirement } \\
\text { (COD) }\end{array}$ & $\mathrm{mg} / 1$ & $>15 \pm 0.176$ & $>15 \pm 0.174$ & $>15 \pm 0.168$ & $>15 \pm 0.160$ & $>15 \pm 0.162$ & $>15 \pm 0.154$ & $>15 \pm 0.153$ & $>15 \pm 0.155$ \\
\hline
\end{tabular}

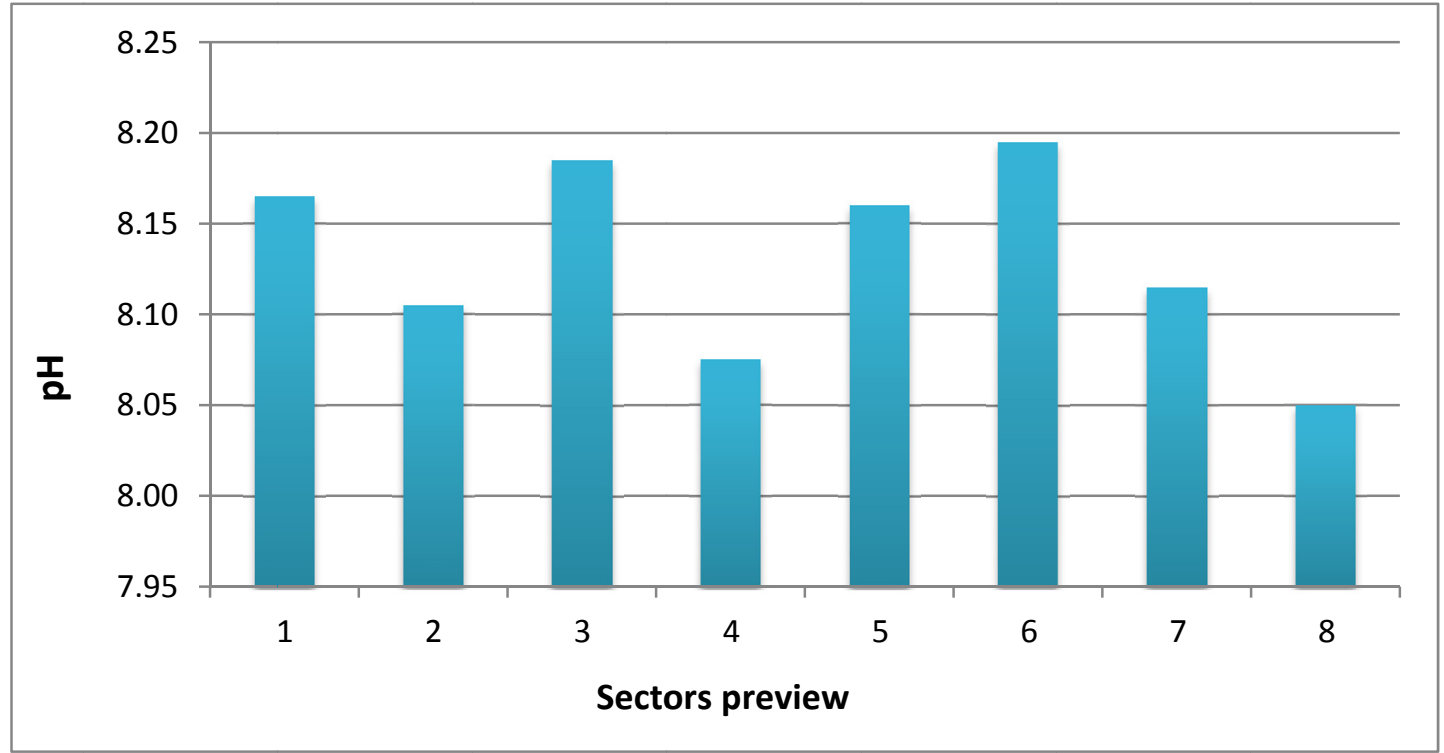

Figure 3. The $\mathrm{pH}$ values in eight sectors of the preview of El-Souda - West Island Kingdom of Saudi Arabia

The proportion of alkaline $\left(\mathrm{CaCO}_{3}\right)$ ranged from of $135 \mathrm{mg} / 1$ to $220 \mathrm{mg} / 1$. Sector 7 recorded the highest values due to the nature of the limestone rocks that underlie the sector. 


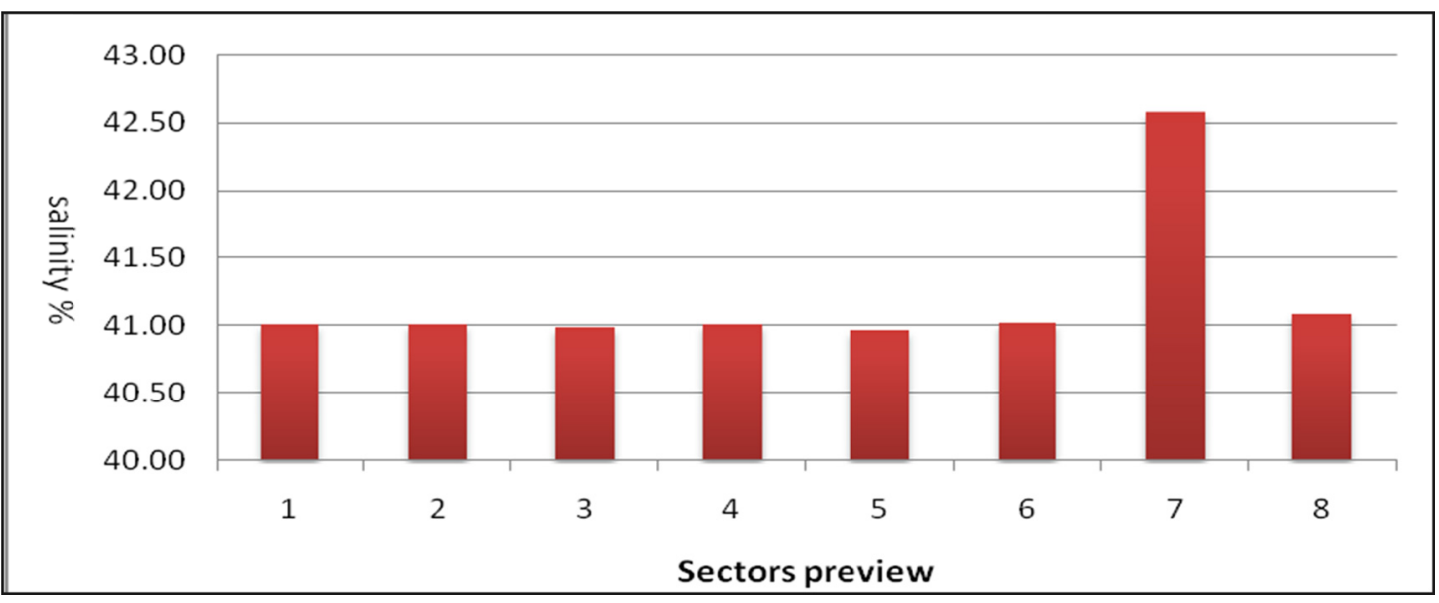

Figure 4. Salinity averages in eight sectors of preview of El-Souda - West Island Kingdom of Saudi Arabia

No strong links between the degree of alkaline and mangrove trees grow was found in this study and this is contrary to what is stated in the study of Pablo and Leonor (2006).

The study indicated that the information on hydro chemical be more pronounced in sectors preview with oldest and most dense trees such as Sector 7 and 8. While the young sectors like Sector 5 don't give clear information on hydro chemical and existence of a any relationship between the properties of water hydro chemical, and among mangroves. This is consistent with the study of Marchand et al. (2011), which indicate that the young mangroves do not give evidence clear geochemistry information like mangrove elderly who usually accompanied by a lot of organic debris, and decrease the amount of $\mathrm{pH}$.

The results showed that the distribution of values of dissolved oxygen (DO) irregular between sectors of the study area, ranging from $3.15 \mathrm{mg} / \mathrm{l}$ to $6.20 \mathrm{mg} / \mathrm{l}$. Sectors 7 and 8 recorded the highest values due to the activity of photosynthesis, and high turbidity of the water. The poor dissolved oxygen DO was found in sector 1 and 2. This may be due to the sang region benthic animals, especially cancers and frequent respiratory roots in addition to shallower water depth (Figure 7). In addition to the proximity of both the open sea reduced the amount of dissolved oxygen. This is in agreement with the study of Marchand et al. (2011), who refers to the role of benthic organisms in the oxygen consumption and increase the organic load.

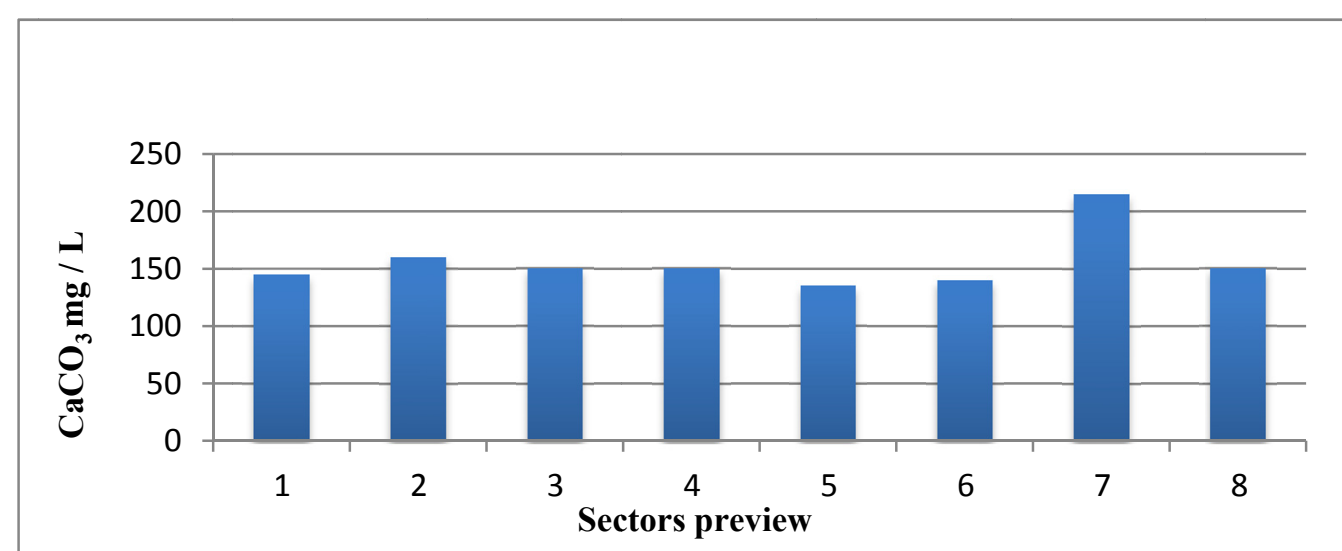

Figure 5. Averages degree of alkaline $\mathrm{CaCO}_{3}(\mathrm{mg} / \mathrm{l})$ in eight sectors preview of El-Souda - West Island Kingdom of Saudi Arabia 


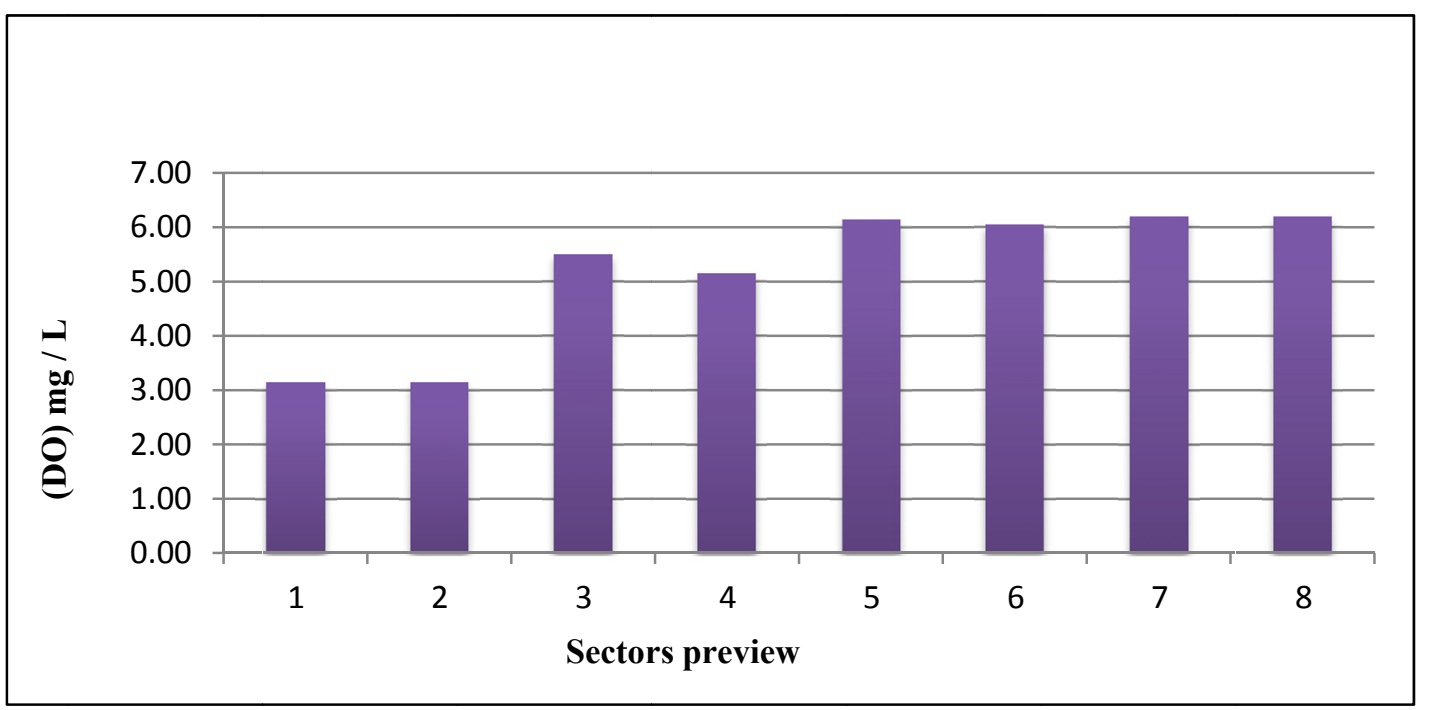

Figure 6. Dissolved oxygen (DO) in eight sectors of the preview of El-Souda - West Island Kingdom of Saudi Arabia
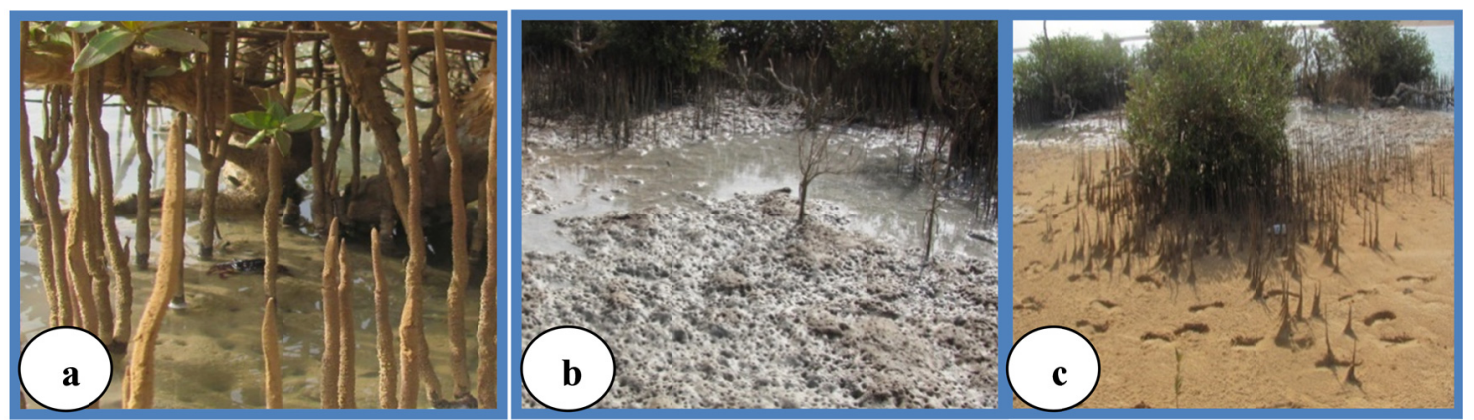

Figure 7. Shallower depth of water and frequent respiratory benthic fauna roots in the sector "(1 and 2) of El-Souda-West Island Kingdom of Saudi Arabia. (a: respiratory roots; b:Organic sediment carbon \& c:: mineral nutrition of respiratory roots)

The results of the index Needing biochemical oxygen BOD, and Needing chemical oxygen COD is less than the limit sensitivity methods that have been used in the estimation of organic pollution which recorded low values $<5$ $\mathrm{mg} / \mathrm{L}-<15 \mathrm{mg} / \mathrm{L}$ in all sectors of the index BOD and COD, respectively, which confirms region free of environmental pollution.

\subsection{The Properties of Vital Nutrients to the Mangrove Community in El-Souda Island:}

The vital nutrients dissolved chemical compounds in natural water are considered the main source of nutrition for organisms in the aquatic environment. Table 2 showed the values vital nutrients to water mangrove community in the study area. From this table, it can be concluded that:

The values of ammonia-nitrogen $\left(\mathrm{NH}_{4}-\mathrm{N}\right)$ ranged between 0.02 to $0.54 \mathrm{mg} / \mathrm{L}$, which are low and located in its entirety within the permissible limits internationally $(0.005-6.2 \mathrm{mg} / \mathrm{L})$. This corresponds to what was stated in the report of the Committee on Environmental Monitoring of Lake Brolos (2012). The low rates values of nitrate-nitrogen $\left(\mathrm{NO}_{2}-\mathrm{N}\right), 0.001-0.006 \mathrm{mg} / \mathrm{L}$, in most preview sectors were less than the allowable limits internationally ranging between $(60-5 \mathrm{mg} / \mathrm{L})$. 
Table 2. Averages the values ( \pm SD) of the characteristics of vital nutrients to water mangrove community in eight sectors of El-Souda - West Island Kingdom of Saudi Arabia

\begin{tabular}{lllllllll}
\hline Property Unit & Sector 1 & Sector 2 & Sector 3 & Sector 4 & Sector 5 & Sector 6 & Sector 7 & Sector 8 \\
\hline$\left(\mathrm{NH}_{4}-\mathrm{N}\right) \mathrm{mg} / \mathrm{L}$ & $0.385 \pm 0.034$ & $0.24 \pm 0.019$ & $0.335 \pm 0.037$ & $0.31 \pm 0.276$ & $0.14 \pm 0.012$ & $0.125 \pm 0.011$ & $0.31 \pm 0.026$ & $0.1 \pm 0.008$
\end{tabular}

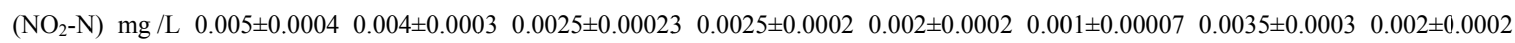

\begin{tabular}{|c|c|c|c|c|}
\hline$\left(\mathrm{NO}_{3}-\mathrm{N}\right) \mathrm{mg} / \mathrm{L} \quad 0.15 \pm 0.011$ & $0.2 \pm 0.016$ & $0.65 \pm 0.053$ & $0.65 \pm 0.049$ & $0.75 \pm 0.058$ \\
\hline
\end{tabular}

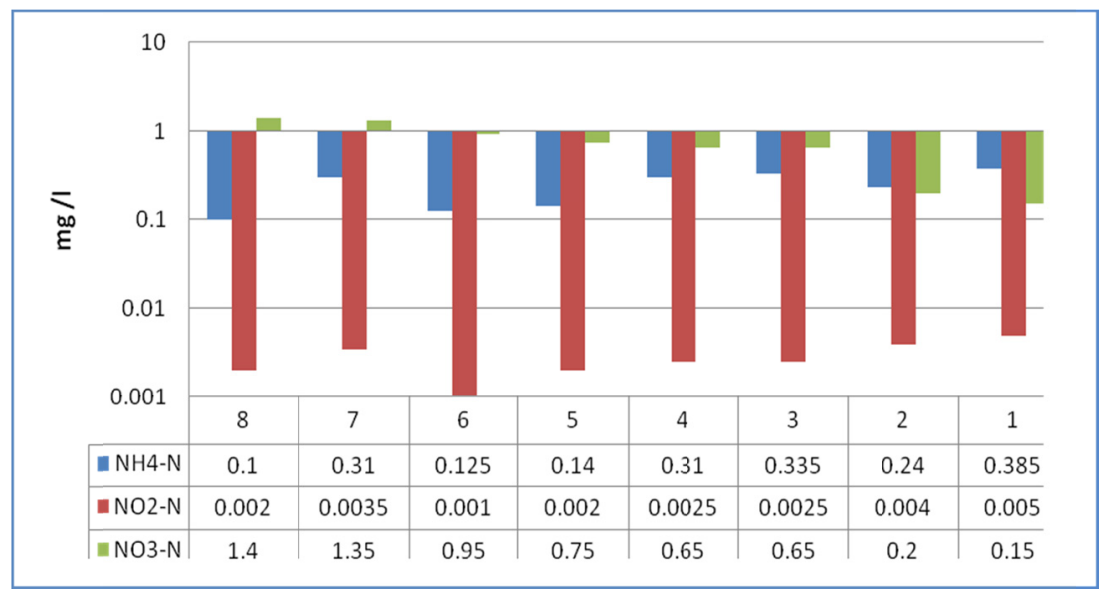

Figure 8. The average vital nutrients in eight sectors of El-Souda-West Island Kingdom of Saudi Arabia

The study showed that the distribution of values of nitrate - nitrogen $\left(\mathrm{NO}_{3}-\mathrm{N}\right)$ is a regular in the study area, ranging from $0.1-1.4 \mathrm{mg} / \mathrm{L}$, recorded high in Sector 7 and 8 as a result of a rich public waste organic, which is in the mildly without limit internationally. This confirms the study area free of organic pollution and the lack of sources of pollution discharged into the waters of Lake Souda Island. This is consistent with the results of a study of Awari and Mulla (2010).

\subsection{The Characteristics of Sediment Organic Mangrove Community of El-Souda - West Island Kingdom of Saudi Arabia}

The analysis of the following results based on the measuring of the amount of organic carbon stored in the sediments of mangroves, both organic carbon oxidized and dissolved degeneration partly O.C or organic carbon dissolved fully forming organic matter OM in addition to the analysis of the content of organic carbon, total TOC stored in the sediments of mangrove. Thus, the amount of inorganic carbon in the sediments, such as salts, carbonates does not enter within this analysis, Table 3 and Figure 9 concluded that:

Table 3. Mean values $( \pm \mathrm{SD})$ of the properties of organic sediment in eight sectors in the mangrove community of El-Souda - West Island Kingdom of Saudi Arabia

\begin{tabular}{cccc}
\hline \multirow{2}{*}{ Sector } & \multicolumn{3}{c}{$\%$} \\
\cline { 2 - 4 } & $\begin{array}{c}\text { Organic matter } \\
\text { O.M }\end{array}$ & $\begin{array}{c}\text { Total organic carbon } \\
\text { TOC }\end{array}$ & $\begin{array}{c}\text { Oxidized organic carbon } \\
\text { O.C }\end{array}$ \\
\hline $0.823 \pm 0.099$ & $0.472 \pm 0.061$ & $0.353 \pm 0.034$ & 1 \\
$0.584 \pm 0.064$ & $0.339 \pm 0.034$ & $0.254 \pm 0.023$ & 2 \\
$0.180 \pm 0.018$ & $0.105 \pm 0.012$ & $0.078 \pm 0.008$ & 3 \\
$0.492 \pm 0.057$ & $0.285 \pm 0.028$ & $0.214 \pm 0.026$ & 4 \\
$0.311 \pm 0.035$ & $0.180 \pm 0.020$ & $0.135 \pm 0.013$ & 5 \\
$0.172 \pm 0.015$ & $0.990 \pm 0.129$ & $0.075 \pm 0.007$ & 6 \\
$0.793 \pm 0.095$ & $0.560 \pm 0.067$ & $0.345 \pm 0.038$ & 7 \\
$1.365 \pm 0.172$ & $0.792 \pm 0.125$ & $0.584 \pm 0.007$ & 8 \\
\hline
\end{tabular}




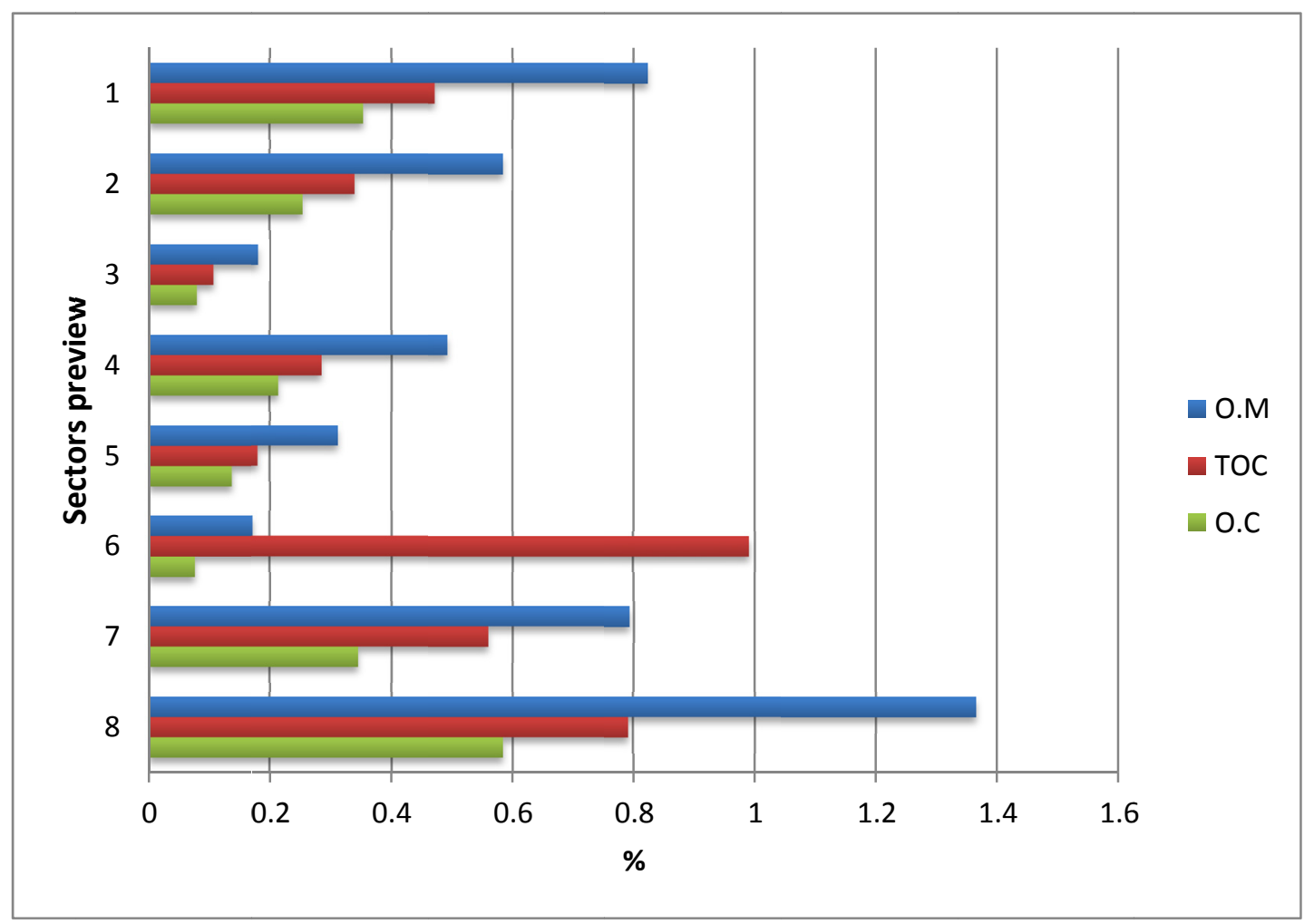

Figure 9. Mean values of various organic sediments in eight sectors of El-Souda - West Island Kingdom of Saudi Arabia

The sector 6 and sector 3 recorded the lowest rate of organic carbon oxidized OC of $0.74 \%$ and $0.078 \%$, respectively. This is due to the lack of decline in mangrove fully in sector 6 and the deterioration of its growth significantly in Sector 3. Sector 8 highest recorded percentage of organic carbon oxidized amounted of $0.593 \%$, due to the density of vegetation of the Mangrove, and the accompanying biological activity of animals benthic, and the increase the volume of organic waste in this sector. This is consistent with Nagelkerken et al. (2008), Furukawa et al. (1997), who found a wide variation in distribution of dissolved organic carbon OC between mangrove sediments, lake water and sediments of mangrove free.

Sector 1 record high percentage of organic carbon oxidized amounted to $0.353 \%$, due to the activity of immersion and recede, and the accompanying exchange of nutrients vital with the sea, and the large benthic fauna especially cancers of different kinds Kristensen et al. (2011).

The values of total organic carbon (TOC) in the various sampling showed low average significantly in sector 6 $(0.099 \%)$, while the percentage of $0.792 \%$ was recorded in sector 8 , suggesting the existence of a significant relationship between the abundance of total organic carbon and an abundance of mangroves trees, accompanied with the activities of different biological in the sediment area. This is consistent with Rajesh et al. (2011), who pointed out that the accumulation of carbon in the plant accompanied by the accumulation in the sediment in the form of organic carbon. The existence of an exchange of materials between the sediments of mangrove and water adjacent coastal was observed (Stefano et al., 2008; Rajesh et al., 2011), which emphasize the role of crabs, and benthic organisms in sediment transport organic, and the effect of the tides in revenue and export of organic carbon to and from the sediment. This may explain the reasons for increase in the rate of total organic carbon TOC $(0.472 \%)$ in sector 1 of the study area (Figure 7$)$.

Organic matter in the soil was found to be low in Sector, 3 and 6 ranged between $0.171-0.180 \%$, respectively, while the highest percentage of organic matter (1.37) in the sediments of sector 8 . This may be due to the intensity of mangrove tree growth and density of plant waste, and the accompanying different biological activities of benthic animals (Figure 10). This is consistent with Alfredan (2006) and Aaron (2008), who refers to the need to maintain biodiversity bottom mangrove forest.

Comparing the results of soil analysis by proximity and then from a pool of mangroves Figure 11, and their relationship to rates of dissolved organic carbon OC, the results of total organic carbon were clear with high 
relationship between the nature of the soil texture and organic sediment values, so that the greater smoothness sediment soil increased rates of organic carbon in its various forms in general, and was clearly shown in soil samples down mangrove-dominated textures silt - Celtic, especially in Sector 7 and 8, and this is consistent with the results of a study (Najeeb et al., 2010), which indicated that soft sediment is more absorption of organic materials than coarse sediment.

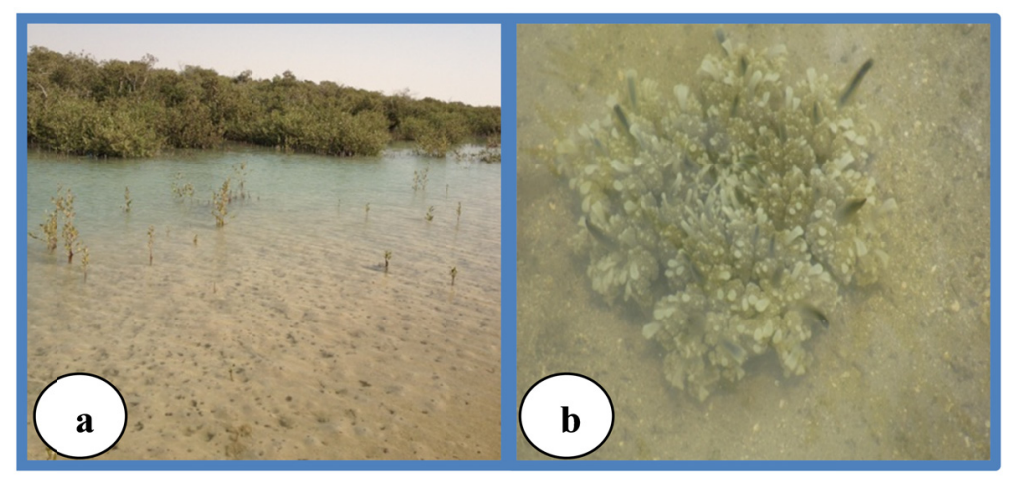

Figure 10. Models of benthic organisms in the sediments of mangrove member of the community of El-Souda West Island Kingdom of Saudi Arabia., plant biodiversity (a\&b)

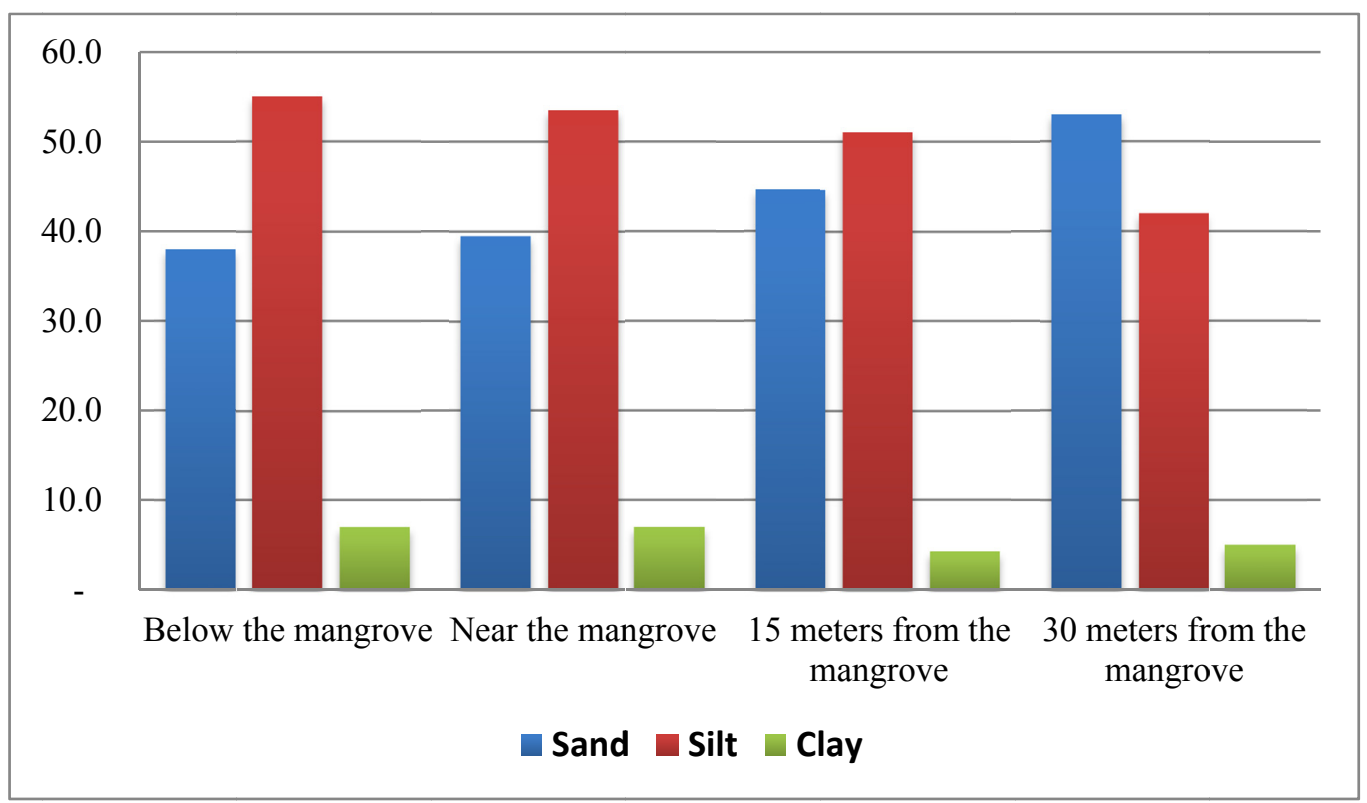

Figure 11. The strength of the soil in eight sectors of the preview by dimension and proximity to the scope of mangrove of El-Souda - West Island Kingdom of Saudi Arabia

This study also, showed that the mineralization and storage of organic carbon was higher in mangrove communities highest lake (parts distant from the entrance to the lake) than gatherings mangroves near the entrance of the lake. This is similar to the findings of Rajesh et al (2011).

\section{Acknowledgments}

This project was funded by the Deanship of Scientific Research (DSR), King Abdulaziz University, Jeddah, under grant No. (377/845/1433). The authors, therefore, acknowledge with thanks DSR technical and financial support.

\section{References}

Aaron, E. (2008). Managing mangroves with benthic biodiversity in mind: Moving beyond roving banditry, Journal of Sea Research, 59(1-2), 2-15. Retrieved from www.researchgate.net/.../222545727 
Albert, J. A., Warren-Rhodes, K., Schwarz, A. J., \& Duke, N. D. (2012). Mangrove Ecosystem Services \& Payments for Blue Carbon in Solomon Islands. The World Fish Center, Solomon Islands. AAS-2012-06.

Alfredan, M. (2006). Study of mangrove communities of the east coast of the Kingdom of Saudi Arabia, Faculty of Science, King Faisal University, Ass.Univ.Bull.Res., 9(1).

Awari, E. H., \& Mulla, A. M. J. (2013). Monitor of spatial changes of coastal environments for the Shuaiba in the western Kingdom of Saudi Arabia. The Egyptian Journal of Environmental Change, 5, 25-70.

Cardona, P., \& Botero, L. (1998). Soil characteristics and vegetation structure in a heavily deteriorated mangrove forest in the Caribbean coast of Colombia. Biotropica, 30(1), 24-34. http://dx.doi.org/10.1111/j.1744-7429. 1998.tb00366.x

Duarte, C. M. (Ed.). (2009). Global loss of coastal habitats-rates, causes and consequences (1st ed.). Fundacion BBVA, Bilbao, Spain.

Duarte, C. M., Dennison, W. C., Orth, R. J. W., \& Carruthers, T. J. B. (2008). The charisma of coastal ecosystems: Addressing the imbalance. Estuaries and Coasts, 31, 233-238. http://dx.doi.org/10.1007/s12237 $-008-9038-7$

Furukawa, K., Wolanski, E., \& Mueller, H. (1997). Currents and Sediment Transport in Mangrove Forests, Estuarine, Coastal and Shelf Science, 44(3), 301-310. http://dx.doi.org/10.1006/ecss.1996.0120

Kristensen, E. Bouillon, S. Dittmar, T., \& Marchand, C. (2011). Organic carbon dynamics in mangrove ecosystems: A review, Aquatic Botany, 89(2), 201-219. http://dx.doi.org/10.1016/j.aquabot.2007.12.005

Marchand, C., Lallier-Vergès, E., \& Baltzer, F. (2003). The composition of sedimentary organic matter in relation to the dynamic features of a mangrove-fringed coast in French Guiana, Estuarine, Coastal and Shelf Science, 56(1), 119-130. http://dx.doi.org/10.1016/S0272-7714(02)00134-8

Margareth, C. (2011). Forests are protected, but carbon sinks in mangroves, seagrasses and marshes are ignored. Nature, 473, 255. http://dx.doi.org/10.1038/473255a

Nagelkerken, I., Blaber, S., Bouillon, S., Green, P., Haywood, M., Kirton, L., ... Somerfield, P. (2008). The habitat function of mangroves for terrestrial and marine fauna. Somerfield, Aquatic Botany, 89(2), 155-185. http://dx.doi.org/10.1016/j.aquabot.2007.12.007

Najeeb, M., Rasul, M., Abushshsa, O., Al-Hazmi, M., Al-Nomani, F., Ahareth., N., ... \& Al-Farawati, R. (2010). Bathymetric Survey and Ground-Truthing of The Al-Kharrar Lagoon, Red Sea Coast of Saudi Arabia. Technical Report SGS-TR-2008-8.

Nellemann, C., Corcoran, E., Duarte, C. M., Valdés, L., De Young, C., Fonseca, L., \& Grimsditch, G. (Eds.), (2009). Blue Carbon. A Rapid Response Assessment. United Nations Environment Programme, GRID-Arendal.

Pendleton, L., Donato, D. C., Murray, B. C., Crooks, S., Jenkins, W. A., Sifleet, S., ... \& Baldera, A. (2012). Estimating global "blue carbon" emissions from conversion and degradation of vegetated coastal ecosystems. PLoS One, 7(9), e43542.

Rajesh, R., Routh, J., Ramanathan, A., \& Klump, J. (2011). Elemental and stable isotope records of organic matter input and its fate in the Pichavaram mangrove-estuarine sediments (Tamil Nadu, India). Marine Chemistry, 126(1-4), 163-172. http://dx.doi.org/10.1016/j.marchem.2011.05.005

Rezende, C. E., Lacerda, L. D., Ovalle, A. R. C., \& Silva, L. F. F. (2007). Dial organic carbon fluctuations in a mangrove tidal creek in Sepetiba bay, Southeast Brazil. Brazilian Journal of Biology, 67(4), 673-680. http://dx.doi.org/10.1590/S1519-69842007000400012 .

Sedjo, R., \& Sohngen, B. (2012). Carbon Sequestration in Forests and Soils. Annual Review of Resource Economics (Annual Reviews), 4, 127-144. http://dx.doi.org/10.1146/annurev-resource-083110-115941

Spalding, M., Kainuma, M., \& Colling, L. (2010). World Atlas of Mangroves, Earth Scan, UK/USA.

Stefano, C., Damien Burrows, S., Fratini, J., Smith, J., Offenberg, F., \& Dahdouh, G. (2008). Faunal impact on vegetation structure and ecosystem function in mangrove forests: Aquatic Botany, 89(2), 186-200. http://dx.doi.org/10.1016/j.aquabot.2008.01.009

Tripati, A. K., Roberts, C. D., \& Eagle, R. A. (2009). Coupling of $\mathrm{CO}_{2}$ and ice sheet stability over major climate transitions of the last 20 million years. Science, 326(5958), 1394-1397. http://dx.doi.org/10.1126/ science. 1178296 
Walkley, A., \& Black, I. A. (1934). An examination of the Degtjareff method for determining soil organic matter, and a proposed modification of the chromic acid titration method. Soil Science, 37(1), 29-38. http://dx.doi.org/10.1097/00010694-193401000-00003

\section{Copyrights}

Copyright for this article is retained by the author(s), with first publication rights granted to the journal.

This is an open-access article distributed under the terms and conditions of the Creative Commons Attribution license (http://creativecommons.org/licenses/by/3.0/). 